\title{
The case of the disappearing glioma
}

\author{
N Buxton, N Phillips, I Robertson
}

\section{Abstract}

A case of glioblastoma multiforme disappearing on CT after a course of dexamethasone is reported. The possibility of mistaking this for lymphoma is discussed. There is no other case similar to this described in the literature.

(F Neurol Neurosurg Psychiatry 1997;63:520-521)

Keywords: dexamethasone; glioblastoma multiforme; CT appearances

Steroids are used extensively for the reduction in tissue oedema associated with cerebral neoplasms. We present a case of glioblastoma multiforme disappearing on consecutive CT after the treatment of steroids so causing us to initially think that this was a lymphoma. Stereotactic biopsy subsequently confirmed histology of glioblastoma multiforme.

\section{Case history}

A 56 year old man presented with a four week history of right sided facial palsy, dysphasia, and unsteady gait. Brain CT showed a left

Department of Neurosurgery, University Hospital, Nottingham, NG7 2UH, UK

N Buxton

N Phillips

I Robertson

Correspondence to: Mr N Buxton, Department of Neurosurgery, University Hospital, Nottingham NG7 $2 \mathrm{UH}, \mathrm{UK}$.

Received 13 December 1996 and in final revised form 4 March 1997

Accepted 22 April 1997

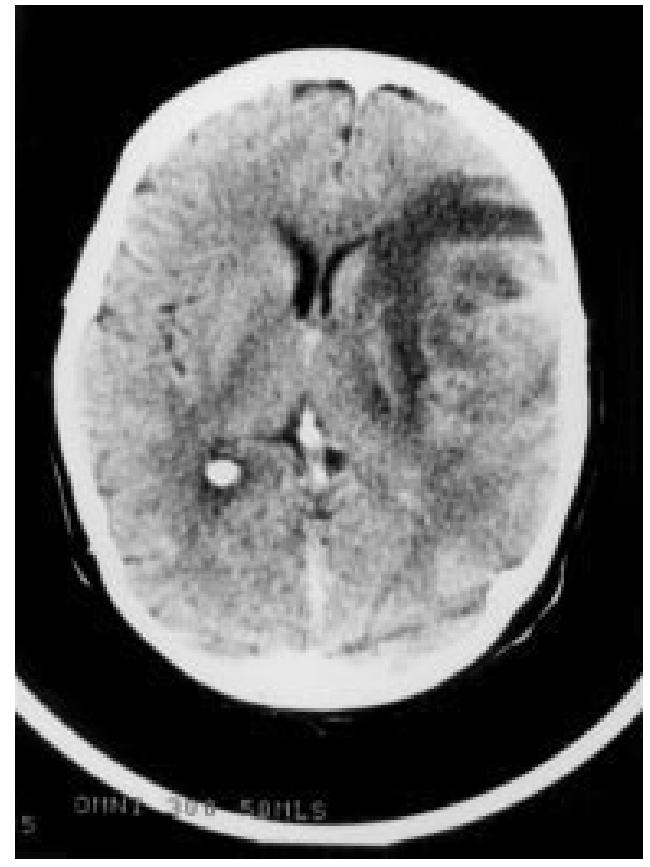

Figure 1 Brain CT showing large right sided tumour enhancing with contrast.

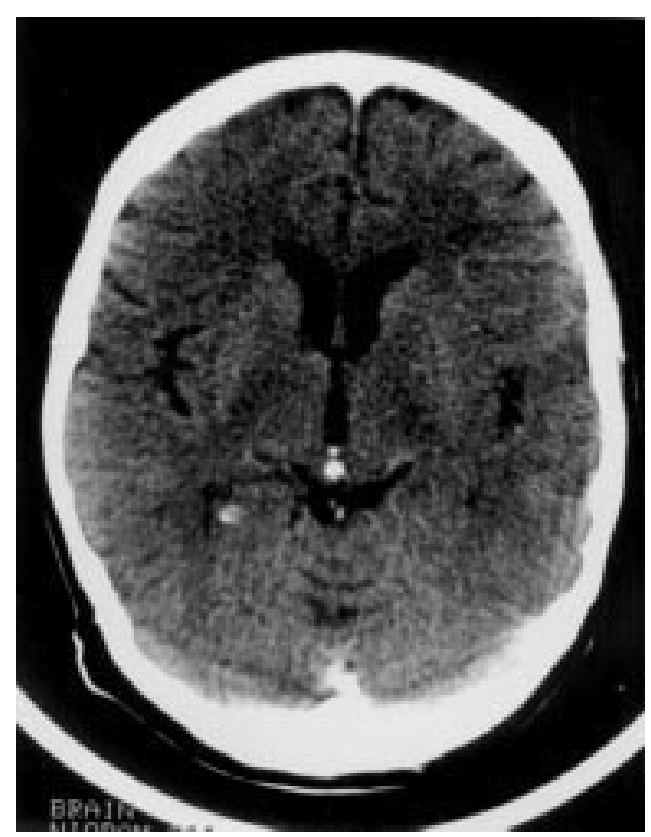

Figure 2 Brain CT of the same patient after his course of steroids. Note that despite contrast the tumour also seems to have disappeared.

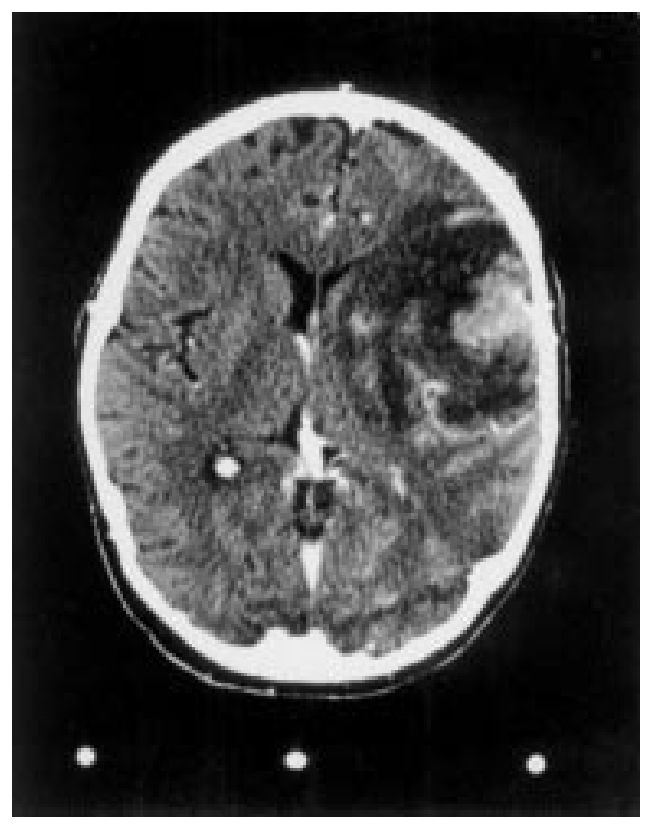

Figure 3 Brain CT taken for the stereotactic procedure showing reappearance of the tumour after stopping the steroids. 


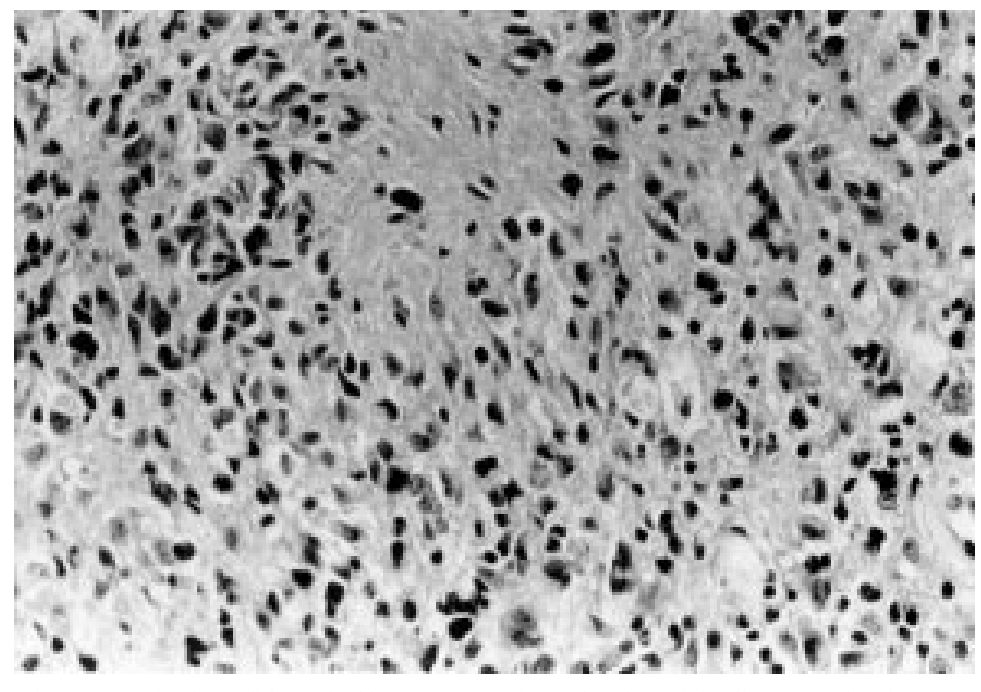

Figure 4 Histology slide of the biopsy. Haemosin and eosin, originally $\times 250$ showing pleomorphic malignant cells which are all positive for glial markers (GFAP).

frontoparietal mass with oedema (fig 1). Five years previously he had been successfully treated for testicular seminoma with chemotherapy. He was started on $2 \mathrm{mg}$ dexamethasone three times daily by the referring hospital. This caused a resolution of his symptoms. His medical history of testicular seminoma and chemotherapy suggested that this mass may have been lymphoma, so repeat scanning at the neurosurgical centre was undertaken which showed that the oedema and the tumour had disappeared even with the use of contrast enhancement (fig 2). Stereotactic biopsy was planned and he was sent home for three weeks without steroids.

He was readmitted for stereotactic biopsy and rescanned (fig 3), the tumour being present again. The clinical course suggested lymphoma. Almost immediately on return to the ward after the surgery, he deteriorated requiring respiratory support. He was transferred to intensive care and was rescanned. The scan showed massive brain swelling. His pupils became fixed and dilated within a few hours and he died.

Histology of the tumour showed glioblastoma multiforme (fig 4).

\section{Discussion}

Steroids are widely used in cases of raised intracranial pressure and are well established in the treatment of tumour associated oedema. ${ }^{12}$ Although it is more than 30 years after their use was first reported, their mode of action is still unknown. ${ }^{1}$ A seven day course of steroids can reduce the peritumoural oedema by as much as $50 \% .^{3}$ It causes a reduction in the apparent tumour volume but MRI volumetric studies have shown this to be only oedema reduction and that the tumour size remains unchanged. ${ }^{4}$

Dexamethasone has become the steroid of choice in brain oedema due to its minimal salt retention and its relative potency when compared with other steroids. ${ }^{5}$ It is used because there can be a $60 \%-75 \%$ improvement in symptoms in patients with brain tumours. ${ }^{6}$ Some of this improvement is undoubtedly due to reduction in oedema but there is also often an improvement in their mood with steroids.

The patient had a reduction in peritumorous oedema, but also had a reduction in the appearance of the tumour bulk which suggested to us that it was lymphoma. ${ }^{7}$ This may, however, be secondary to suggestions that glucocorticoids have a tumoricidal effect on glioma cells. ${ }^{89}$

\section{Conclusion}

The use of steroids is, and will remain, a very useful therapy for improving the clinical state of patients with brain tumours. Their mode of action is not known. Our case illustrates that you cannot be sure what the lesion is unless you have tissue for histology. It also shows that steroids can reduce the peritumorous oedema and apparent tumour size so that the tumour effectively disappears on the scans.

We thank Dr Keith Robson, University Hospital, Nottingham, for his help with the preparation of the histology slides and the accompanying annotation.

1 Galicich JH, French LA, Melby JC. Use of dexamethasone in treatment of cerebral oedema associated with brain tumours. Lancet 1962;81:46-53.

2 Kofman S. Treatment of cerebral metastases from breast carcinoma with prednisolone. $\mathcal{F} A M A$ 1957:163;1473-6.

3 Andersen C, Astrup J, Gyidensted C. Quantitation of peritumoural oedema and the effect of steroids using NMR-relaxation time imaging and blood brain barrier analysis. Acta Neurochirurgica 1994;60(suppl):413-5.

4 Galloway RL, Maciunas RJ, Failinger AL. Factors affecting perceived tumour volumes in magnetic resonance imaging. Ann Biomed Eng 1993;21:367-75.

5 Weissman DE. Glucocorticoid treatment for brain metastases and epidural spinal cord compression: a review. $\mathcal{F}$ Clin Oncol 1986;6:543-51.

6 Coia LR, Aaronson N, Linggood R, Loeffler J, Preistman TJ. A report of the consensus workshop panel on the treatTJ. A report of the consensus workshop panel on the treat-
ment of brain metastases. Int $\mathcal{F}$ Radiat Oncol Biol Phys ment of brain

7 Singh A, Strobos RJ, Singh BM, et al. Steroid induced Singh A, Strobos RJ, Singh BM, et al. Steroid induced
remissions in CNS lymphoma. Neurology 1982;32:126771 .

8 Mealy J, Chen TT, Schanz GP. The effects of dexamethasone and methyl prednisolone on cell cultures of human glioblastoma. F Neurosurg 1971;34:324-34.

9 Sherbert GV, Lakshmi MS, Haddah S. Does dexamethasone inhibit the growth of human gliomas? $\mathcal{F}$ Neurosurg $1977 ; 47: 864-70$. 